\title{
Students' Perspectives on Pathways to University Readiness and Adjustment
}

\author{
Louise Wasylkiw \\ Correspondence: Louise Wasylkiw, Department of Psychology, Mount Allison University, 49A York St., Sackville, New \\ Brunswick, E4L 1C7, Canada
}

Received: November 12, 2015 Accepted: November 23, $2015 \quad$ Online Published: December 4, 2015

doi:10.11114/jets.v4i3.1197

URL: http://dx.doi.org/10.11114/jets.v4i3.1197

\begin{abstract}
The transition from high school to post-secondary education is often difficult for students. The literature examining factors that foster a successful transition generally focuses on previous academic achievement and/or individual differences that enable students to navigate the culture of university. Through interviews with first year university students $(N=19)$, the present study conceptualizes student readiness as a match/mismatch between an individual's attributes and the requisites of the academic and social milieus of university. This phenomenological investigation situates the development of a work ethic as central to a successful transition to university and contributes to the limited research conducted concerning the pathways that optimize student readiness.
\end{abstract}

Keywords: university readiness, transition to university, university students, academic preparedness

\section{Introduction}

\subsection{The Transitional Process}

According to Statistics Canada (2013), record numbers of students are pursuing post-secondary education. For many, the transition from high school to post-secondary education is not an easy one. Indeed, research shows that dropout rates in Canadian universities are highest between first and second year, and range between 20 to 24\% (Finnie \& Qui, 2008). The successful transition from high school to university has been conceptualized as multidimensional insofar that it involves ability, perceptions, attitudes, and behaviours as they relate to navigating a new academic and social environment. The existing literature on the transition to university is diverse and one way to integrate and organize the research findings is to consider an overarching theoretical framework. In addition to synthesizing existing research, such a framework would provide a common language, outline the patterns of interrelationships of concepts, and identify gaps in knowledge.

Briggs, Clark, and Hall (2012) proposed a model of the transitional process that may be useful as such a framework. Briggs et al.'s process model highlights students' development as a learner in higher education and situated this identity development centrally with corresponding organizational influences that support a successful transition. In the present research, I examine students' perceptions of a successful transition to university with a specific focus on factors that foster and factors that inhibit readiness and adjustment. The primary goal was to determine if Briggs et al.'s model of organizational influence on the development of learner identity was substantiated through qualitative analysis of students' views. I begin with a brief review of extant literature of transition issues and the factors that predict adjustment followed by a detailed description of the present study.

\subsection{Transition Issues}

Transitioning to university often entails adjusting to a new environment that poses distinctive academic and personal challenges. From an academic standpoint, it is widely accepted that university is different from high school and several North American universities provide a list of those differences for incoming students. For example, the University of Regina (2015) lists the differences that capture the uniqueness of the academic environment in university. Most notable is the expectation of independence and the transfer of responsibility from the external to internal; specifically, compared to high school where teachers remind, guide, and structure learning, in university, the responsibilities and direction come from the student. Together with larger classrooms, multiple teachers, and a more demanding workload, students face differences in university academia compared to high school. 
The personal challenges students experience when transitioning from high school to university are well documented and include: forging new relationships, living apart from family, feelings of anonymity in classrooms, adjusting to new living arrangements, and financial concerns (e.g., Briggs et al., 2012; Hanlon, 2012). Indeed, there is evidence that new students struggle with homesickness and loneliness (Wei, Russell, \& Azkalik, 2005) as well as stress, anxiety, and depression (Dyson \& Renk, 2006; Sasaki \& Yamasaki, 2007). Such difficulties have negative consequences for physical health (e.g., Adams, Wharton, Quilter, \& Hirsch, 2008) and academic success (e.g., Andrews \& Wilding, 2004). Thus, personal challenges contribute to perceived stress and require that students master developmental tasks of self-regulation and independence.

\subsection{Predictors of Transition}

Given the transition issues students face, it is not surprising that researchers have explored what factors predict successful transition from high school and adjustment to university. Although demographic factors such as higher socioeconomic status (SES) (e.g., Sackett, Kuncel, Arneson, Cooper, \& Waters, 2009) and gender (e.g., Christofides, Hoy, Li, \& Stengos, 2008) may be important, most of the literature focuses on factors that fall into two categories: (1) previous academic performance and cognitive ability and (2) individual differences.

High school academic performance is a consistent predictor of academic success in university. For example, in a large sample of first-time freshmen entering university Geiser and Santelices (2007) found that high school grade point average (GPA) was the strongest predictor of grades across all years of an undergraduate degree outperforming standardized test scores. In a 2012 review and meta-analysis, Richardson, Abraham, and Bond reported medium sized correlations between high school GPA and post-secondary GPA. Other research shows the predictive power of post-secondary admissions tests that assess general cognitive ability like the SAT (Scholastic Aptitude Test). For example, Sackett et al., (2009) used multiple data sets to demonstrate that even when controlling for SES, performance on standardized tests predicted post-secondary grades. Whereas this research demonstrates the importance of high school grades and cognitive ability for academic success, it also highlights the fact that variance in university GPA is not fully accounted for by previous academic performance and general ability (Furnham \& Chamorro-Premuzic, 2004).

Founded on the idea that individual difference variables incrementally add to the prediction over and above demography and previous academic achievement, a number of variables have been identified as being important. Perhaps one of the most robust individual difference predictors for post-secondary achievement concerns motivation (Christofides, Hoy, Milla \& Stengos, 2015). Indeed, in their 2004 meta-analysis, Robbins et al., identified the motivation to achieve as being most strongly related to post-secondary GPA where achievement motivation appears to reflect students' persistence in the face of academic challenges (Richardson \& Abraham, 2009). Thus, other individual difference factors that also capture persistence show similar relationships to academic achievement. For example, the personality trait of conscientiousness contributes to the prediction such that students who score high on a measure of conscientiousness also have higher GPAs in post-secondary education (O'Connor \& Paunonen, 2007). Such aspects of motivation and personality appear to affect academic performance, in part, because of their influence on behaviour; for example, Conrad (2005) showed that conscientious students were more likely to attend classes compared to their low conscientious counterparts. Other behaviours related to studying and learning also meaningfully contribute to success such as writing, reading, presenting, and preparing for tests (e.g., Crede \& Kuncel, 2008).

There is a growing awareness that the stress associated with the transition to university has the potential to negatively impact adjustment. Although the research has not generally supported the relationship between stress and academic achievement, it seems reasonable to suspect that stress has a role in successfully transitioning to university when one considers that a successful transition involves more than just academic achievement. As such, a number of psycho-social variables do predict important outcomes related to adjustment. For example, one's ability to manage stress, to navigate the social environment of university life, and to adapt to differing demands all characterize successful students (e.g., Parker, Summerfeldt, Hogan, \& Majeski, 2004). Moreover, engagement with and commitment to the social and academic environment contributes to retention (e.g., Tinto, 2012). Still other research identifies various factors that foster coping such as optimism and social support (e.g., Dawson \& Pooley, 2013).

Given the presumed importance of many of the individual differences, it is not surprising that researchers have developed inventories targeting these variables. For example, Prevatt et al.'s (2011) Academic Success Inventory for College Students (ASICS) provides an assessment of a variety of variables including: career decidedness, socializing, anxiety, and internal motivation/confidence. Scores on the ASICS were found to predict GPA and was shown to be useful for identifying students at risk academically. As another example, Wintre et al. (2009) developed the Student Perception of University Support and Structure scale (SPUSS) to assess students' perceptions of academic expectations and availability of support and found that high scores on the SPUSS predicted adjustment to university.

In sum, previous researchers have explored the factors that contribute to student success in university. These research 
endeavours have focused on demographic factors, previous academic performance and various individual differences important for motivation, study behaviours, and management of stress and change. Unique to Briggs et al.'s (2012) model of transition is the idea that to achieve in university, students must develop a learner identity. Thus, the process begins with students imagining and aspiring to attend university which, in turn, contributes to formulating expectations and acquiring relevant skills and knowledge. Together, these influence students' commitment to a university education. The process of identification (as a learner) occurs with the onset of university education when students adjust to the environment, gain confidence, and autonomy, and succeed academically. It appears then that the literature examining contributors to a successful transition to university is embedded in Briggs et al.'s model but not clearly delineated. One way to corroborate the idea that a successful transition to university involves identity development is to ask students.

\subsection{Overview of Present Study}

To examine student readiness for university, a qualitative design was adopted as this method would lead to identifying themes that would facilitate the understanding of the complexities involved. Therefore, in the present study, first year undergraduate students were interviewed about their experiences with a particular focus on understanding the unique challenges that inhibit and the factors that foster adjustment and success in university. The information garnered from these interviews was used to propose a preliminary description of the identity formation of students as they transition from high school to university. By doing so, the antecedents of adjustment are outlined and they reflect the uniqueness of this transitional period.

\section{Method}

\subsection{Design}

Interviews with first year undergraduate university students were conducted to identify common pathways and barriers for readiness for university and successful transition from high school. Interviews were chosen as the method for three reasons. First, this method allows a depth of investigation not found in survey research. In other words, although there was a specific set of guiding questions, students' responses were not constrained by predetermined questions and answer formats. Moreover, responses could be explored in depth. Second, in comparison to a focus group approach, a one-on-one interview would provide a safe place for participants to reveal and expand on their experiences and feelings which might be hindered in a group setting. Third, through the identification of themes across interviews, clear links between what participants say and common pathways and barriers for readiness and transition would emerge. Interviews were subsequently transcribed and an iterative process of comparing participants' responses to emerging themes and concepts highlights commonalities.

\subsection{Participants}

Nineteen first year students (13 females; 6 males) enrolled in a small liberal arts college in a small community in Eastern New Brunswick volunteered to participate in return for course credit. Students ranged in age from 18 to 21 years $(M=18.632, S D=0.831)$ with nine students reporting being 18 years of age. Three participants identified as international students (two identified as Asian and one as American) whereas 11 of the remaining 16 originated within the Atlantic region of Canada. Given the descriptions of their hometowns, six participants were from rural (vs. urban) areas. All participants were enrolled in their first year of university and had not previously attended any other post-secondary institution. Additionally, all participants lived in residence during their first term with two participants indicating alternative living conditions at the start of the second term of their first year.

\subsection{Procedure}

All interviews were carried out between February and March of the second term of first year. All interviews were carried out by a recent university graduate who was employed as a research assistant. The female research assistant was deliberately hired to conduct the interviews to ensure ease of dialog and comfort for participants because the interviewer was close in age and had recently undergone a similar transition. Interviews were audio-taped in a research lab in the university's department of psychology and lasted approximately $45-60$ minutes. Transcribed interviews were coded into categories that reflected common themes. Guiding questions are provided in the appendix.

\section{Results}

Themes extracted from interviews are organized into five categories including: (1) attending university, academic achievement, residence and social culture, independence and life skills, and personal attributes. Given students' descriptions, readiness may best be defined as one's preparedness to navigate the academic and social environment of university. This definition of readiness and its characteristics are captured by a match between previous academic training and the current academic culture as well as a match between individual development/functioning and the current social culture of university. Importantly, the match (or mismatch) in academics and in the social culture is driven by a number of factors as outlined in the following sections. Each theme is expanded on with the use of exemplar 
quotations that highlight the duality of each such that both assets and barriers to readiness and the successful transition to university are described.

\subsection{Attending University}

When asked their reasons for attending university, participants voiced similar aims and goals for the future. Specifically, all participants noted that they needed a university degree to get a job. Indeed, most participants (15 of 19) described a university education not only as essential for future employment but as an expectation. For example student \#2 said:

I think mostly I just never had the thought to not go to university. They [parents]

always wanted us to know, like from a young age, that that was the expectation, like the

expectation was there unless there was like a huge reason not to go.

Importantly, the expectation of attending university was not limited to family as student \#10 noted "Well, I wanted to first of all, but it was also kind of what every one of my friends did. So like there's kind of a stigma involved in not going." Thus, it appears that among this sample, acquiring a university education is a general expectation held by family and friends of students

\subsubsection{Goals and Commitment}

All participants responded in the affirmative that they intended to complete their undergraduate degree and further described a high level of commitment, however, when asked to expand on their long term goals with respect to university, participants struggled with articulating clear goals as relayed by student \#4: "I think something will jump out to me eventually." In contrast, only 3 students described specific plans for the future such as Student \#13: "My plan now is to be a doctor so I just knew this is the path I had to take." Not surprising, it appeared that those who expressed clear goals also expressed the strongest level of commitment to their education.

\subsubsection{Differences between High School and University}

Overall, participants noted that university life was different than high school requiring a transitional period of adjustment. Interestingly, only two of the 19 students interviewed described the transition as difficult yet all described similar challenges including higher volume of academic work, increased independence, and more opportunities for socialization. Additionally, all students described individual factors that would facilitate adjustment including self-management, being outgoing, and having clear goals.

Each student interviewed noted a lack of academic preparedness coming from high school. In line with some commentaries about high school curricula (e.g., Slavin, 2007), students reported that in high school, learning was constrained to the school day, deadlines/due dates were flexible, and that content was spoon-fed to students. Students noted that the primary difference between high school and university classes concerned the volume of work as student \#15 suggested: "It's not harder than high school, like learning the material and stuff, but it's just there's a lot more material."

\subsection{Academic Achievement}

In the present sample, students realized that academic success in university was tied to a work ethic not required in high school. Such a work ethic encompassed study skills, time management, and self-regulation. Study skills included: attending classes, reading, note taking, distributed studying, and study groups. For example, student \#8 suggested that "... in high school, they give you all your notes" and it would have helped to "know how to like properly read documents, articles, and like write notes out of them". Despite the disconnect between the skills fostered in high school and those required in university, students emphasized time management as critical for academic success. One reason for this emphasis may be linked to the nature of the material. As student \#2 suggested:

I find I need to give like a lot more time to do things in order to do well than I did in high

school. I can't just read something once and understand it. Like I'll read something once,

and I'll understand it, then I'll read it again and I'll slowly like pick up on little things.

\subsubsection{Development of Needed Work Ethic}

Although students felt that high school was generally inadequate in preparing them for university, the required work ethic was fostered by advanced placement in high school (college level courses offered in high school), the International Baccalaureate Diploma program (IB; university credited courses offered in high school), and CEGEP (College of General and Professional Education; a two year program following grade 11 that targets a specific program of study). As student \#4 noted that university was "really similar to CEGEP. ...it wasn't like a big adjustment". Such programs appear to cultivate the needed work ethic in several ways including having: independent readings, multiple teachers, 
regular essays, and midterm examinations as assessment. As student \#13 noted such programs instilled habits associated with a heavier workload: "I honestly forgot all of it [the content of courses in IB] but...it helped with just like getting used to having like a heavier work load was good".

Time management and self-regulation skills also arose from the employment experiences students described. Specifically, students suggested that employment promoted a sense of responsibility as explained by student \#14:

I'd have to like figure out how to get everything done in time and understand how

everything worked... and also I guess like working a public place you're dealing with the

public a lot so it gives you good people skills I guess, and problem solving skills type of thing

Part time employment during high school appeared to expose students to competing demands and provided students with an opportunity to develop confidence in their own decision making as student $\# 2$ suggests in the following quote:

But I think having too much to do really helped me. Because it helped me get my

priorities straight. And when you have too much to do, you stay on task because you

can't not stay on task. And I think working on it taught me a lot of independence, a lot of

independence, especially when you'd be working on the weekends and somebody would

come tell you...And like it really teaches you to think on your feet. That was really

important, really important, just knowing how to relax and go with the flow. When things

don't go the way they're supposed to you just deal with it because that's...you think something will go well and it doesn't and you just have to cope with it. I think working was huge for me.

The idea that employment contributes to confidence is in line with Bandura's (1977) concept of self-efficacy that others such as Wei and colleagues (2005) highlight as important in adjustment to post-secondary education. As student \#17 notes employment “...provided me with a heightened sense of like responsibility, having dealt with like situations when things don't go according to plan or when um, you're called to do something that needed the organization and like, the responsibility piece of that in that I know when I have to take responsibility and when um when I have to act."

\subsubsection{Beyond Frosh Week}

Given the general expectation about acquiring a university education, the transition appears to be most salient when students first arrive on campus. Overwhelmingly, students reported positive views of the activities designed to orient and welcome incoming students during the first week; all students recognized the importance of the first week for community building, however, students also suggested that it failed to prepare them for the academic culture. For example, student \#12 said:

When I got here, I had no idea how to sign up for classes. I had no idea what I was doing,

I didn't know how to make a schedule, didn't know how to use whatever it is, Connect [a scheduling software program used by the university]. Nobody really told anybody that. We just had to kinda like figure it out on our own.

As one student suggested the activities of the first week did not mirror what followed: "..the biggest transition was coming here and there was so much to do and it was really fun and there were so many people to meet....then all of it just going away... as soon as class started, there was no time for that" (student \#1).

\subsubsection{The Illusion of Time}

The two attributes of time management and self-regulation highlight a key issue that all students talked about. Specifically, the lack of structure led to a perception of too much time as revealed by student \#16: "Having time between your classes and not being in school for like seven hours a day." Additionally, the perception of time likely contributed to procrastination as student \#1 pointed to: "I have all this time and it's like oh, I can study here and when it comes time to study, like oh I can do it later." The lack of a daily routine meant that students wavered between the feeling of having a lot of time and the feeling of being pressured as captured by student $\# 5$ : “...there are some days where I just come home and there's nothing left in me because there was so much [crammed schedule of classes] but then there's some days where it's just, I've got so much free time." Several students suggested that more effective studying arose when they themselves imposed structure as indicated by student \#15:

When I get started on something, I start like trailing off so like, if I'm not like really busy

and be like ok, I have like one hour to study like get the most amount of time, if I had

maybe like five hours in a night, maybe I'd sit down and start playing on my computer, 
and then time just starts like rolling and then I'd be gone. So just keeping myself busy it

just, it forces you to manage your time and use your time productively.

Interestingly many of the skills and attributes students identified as contributing to academic success are also considered desirable for successfully navigating the social milieu associated with the transition to university.

\subsection{Residence and Social Culture}

Given the residence life of the students in the present sample, one challenge identified was the increased opportunity to socialize and the noisiness of sharing accommodations, both of which hindered a focus on academics. Yet, at the same time students expressed a need and a desire for the social aspects of university.

As student \#1 noted, opportunities for involvement requires strategic planning and decision making:

There's always a lot going on, which is nice but at the same time, um, the times that they

have certain events conflicts with the times I study. For example, last night they had

Zumba at like 7 and I like to exercise so I went but I know I probably should've been

studying for a midterm I have Thursday. You can kind of do whatever you want but to also keep in mind too that you can't do everything you want, like it's still about school and I think a lot of people forget about that.

The biggest distraction from academics appears to come from the spontaneity of the social milieu of residence as described by student \#2:

There's so many times where I know I should be studying. Like I hear music down the

hall or somebody's doing something and then I do find it hard. Especially on the weekends, cos on the weekends I always plan to do things but it can never actually happen. Because on the weekends, nobody else is doing things. I mean that really does affect me because I do like the weekends because I like having that big time to just do something, but I never do.

\subsubsection{Residence and Academics}

The distractions afforded by living in residence necessitated that students must find a safe place for academic work. Such a place is often located away from residence (i.e., library) and is not necessarily convenient as student \#14 described: “...then sometimes it's hard to focus and you'll have to leave and go somewhere else which kinda sucks" and by student \#8: "I would say I could never work in my room. Never, never, like I would never be able to work in my room. I'd always have to go to the library or one of the work lounges." Importantly, sharing accommodations did not just impact students' academics as student \#11 suggested: "I found it hard to not have like your own space.....if I wanna call my parents and just have a private conversation there's nowhere you can really do that". Student \#16 found the lack of privacy to be difficult: “...it's just weird not having your own bathroom, kitchen, ...it's really hard to get used to."

\subsubsection{Social Networks}

Although living in residence and the increased opportunities to socialize hindered studying and a focus on academia, students generally agreed that the social environment was one that fostered a sense of belonging and integration within the community. As one student said: “... it's easier to get through the day if you have people around you who care about you." (student \#14).

With the initial transition to university, several students in the present sample commented on the advantage of knowing a fellow student prior to arrival. Specifically, having a friend from high school or a family member already attending the same university appeared to counteract feelings of anxiety or stress as articulated by student \#16: "My roommate....she was my friend from high school. It would be hard like doing things all on your own." Student \#14 also described the comfort in knowing someone: "I'm like very family oriented so it's nice, like my cousin lives next door to me so it's nice to have a little aspect of family."

The importance of others for familiarizing incoming students with the physical and social culture cannot be overestimated: "I think I had an easier time than most people just cos like my sister went here and I came to visit a couple of times and I even went out with her a couple of times." (Student \#19). But the advantages of knowing another student extend beyond a feeling of belongingness to include guidance. For example, student \#18 suggested that “.....it gives you someone to like you can relate to and like they can give you some pointers."

The advice from family and friends, independent of whether they are also on campus, appears to be relevant for student success as noted by student \# 14: “...they were all giving me like advice and tips and were like oh, you need this and ... gave me a big long list of everything I should buy to take to university with me which is very useful." Reducing feelings of alienation and loneliness may be promoted by the physical proximity to family. In other words, students who were 
able to return to family regularly saw that as an advantage. At the same time, other students recognized the value of not going home for promoting independent living:

My parents didn't let me come home. ... if it got awful they would probably come and get

me, but they said they would come see me as much as I wanted them to...if you always

go home you're always going to turn back into that person that relies so much on

everything they had at home." (student \#2)

\subsection{Independence and Life Skills}

Participants were asked to consider the attributes needed for success. The first response by all students related to self-regulation making it clear that students struggle with competing demands and prioritizing the same as described by student \#17:

Seeing if I have like three midterms in one week, well that's worth the most, where most of my time deserves to be for studying. Um, and how to balance that with the sports, clubs, and everything else I like to do in university.

Students recognized that self- regulation enabled the required work ethic that was described earlier:

I'd say time management and just like actually putting the work in. I know for me like procrastination was a really bad thing. Like I just couldn't seem to sit down, but I think you need to be able to concentrate and just like get things done but also put effort into it too, not just like getting it out of the way. (student \#1).

In addition to having the ability to self-regulate, students noted the shift to independent living that accompanied the transition to university:

It goes from being in high school where you have to ask permission to go to the

bathroom, to going to university where you have to do everything for yourself and like

make your own doctor's appointments and buy your own things and make your own

schedule and work out all your own time. (student \#12)

On the one hand, students suggested that a lack of preparedness for many activities of daily living including management of one's finances to doing laundry exacerbated other transitional issues: “...you don't really have someone, like I guess my mom like cleans all my stuff and that stuff. So I didn't, it was hard to do all that stuff on my own" (student \#16). At the same time, students appeared to take pride and joy in independent living:

But like here you're on your own, like if you need to go like to the hospital or anything, you're doing that by yourself. Um it's also kind of cool too, like to think you are on your own like where you're taking care of yourself, like you've made it this far, like you're doing what you're supposed to be doing. And I find like I've already noticed a difference in myself too like, at home like my parents come to things with me and stuff whereas like here, you are on your own. (student \#1)

\subsection{Personal Attributes}

Of all the personal attributes that students identified as beneficial for the transition to university, the most commonly reported was being outgoing and open. As student \#17 said: "You need to make social connections...without those university can often be like hell". Although not all students are outgoing, the need to "put yourself out there" (student \#14) would contribute to maximizing the entire university experience. Such personal attributes could be developed: “... work helped with my social skills a lot I think more than anything like, being able to talk to strangers and like make friends and stuff and just come out of my shell" (student \#19).

\subsection{Summary of Results}

The above themes were extracted from transcripts of the interviews over several iterations so that no themes were left uncovered. Interestingly, it became clear that there was no one experience or attribute that would signal readiness and no one construct that would predict a successful transition from high school to university. Indeed, it appears that during this developmental milestone, the challenge is not in dealing with any one issue but rather having multiple changes simultaneously occur. Indeed, many students noted that the difficulty with transitioning to university was not due to any one factor but the combination and the importance of each for the individual. For example, student 14 concluded that: "it's different for different people when you are ready".

Given the interviews in the present study, one might characterize the student who successfully transitions as one whose academic and social background matches that of the university setting. This match is likely advanced by a work ethic that may evolve through maturation and/or by having experiences that foster a match between the needed skills and the 
academic culture of university. However, successful transition is not restricted to academic adjustment and success. Importantly, the social milieu of university and of residence life specifically is one that requires careful navigation. Successful navigation in this domain appears to come from similar attributes that foster success in academics.

\section{Discussion}

The present study was undertaken to examine students' perceptions of what contributes to readiness for university and the factors that facilitate and challenge a successful transition from high school. Given the vast literature concerning the transition from high school to post-secondary institutions and the diverse set of constructs that researchers have identified as predictive of a successful transition, the goal of the present study was to determine if students' perceptions corresponded to Briggs et al.'s (2012) model of learner identity. Whereas the development of a learner identity is important for academic success, the findings reported here suggest that readiness is key for success. Some like Conley (2009) provide a definition of this construct of readiness for post-secondary education that focuses on academic-related preparation. The results of the present study further the understanding of what readiness is. Specifically, readiness for university cannot be characterized by a set of skills and a constellation of particular attributes rather readiness might be better thought of as a match between existing attributes (including academic related abilities) and the culture of the university setting that begins with the decision to attend university. Three findings from the present study are noteworthy and expanded on below including: the decision to attend university, academic preparedness, and social readiness.

The results of the present study suggest that an understanding of student readiness and transition from high school to university begins with a student's decision to attend university. Once made, such a decision would appear to commit students to their program of study. Given the economic landscape, students voiced a societal expectation of a university education for employment. This expectation was reinforced by family and friends. Yet not all students in the present sample adopted those standards as their own. In other words, unless the decision to attend university arose from their own goals, commitment and motivation may not be high enough to sustain them throughout their degree programs. One implication is that internalization of the standard of attaining a university education likely works in conjunction with academic preparedness and social readiness.

Academic preparedness emerged as a strong theme in the present sample. One aspect includes specific skills such as note taking and critical reading that begin to develop prior to enrollment in university. Thus, the differences between high school and university were described by students in the present sample and these differences are well recognized as seen in the University of Regina's (2015) guide to transition. One novel finding in the present study was that students appeared to be advantaged by experiences such as advanced placement in high school or part time employment because those experiences fostered independence and self-regulation, attributes needed for the development of a work ethic required in university. Thus, students who described involvement in either advanced placements in high schools or employment, appeared to have the best match between their current states and the academic culture of university. This observation, in part, stems from the words that participants used in describing their experiences such as acquiring responsibility and learning to be confident in decision making.

Importantly, academic preparedness defined as a work ethic appears to correspond to Briggs et al.'s (2012) stage of learner development. In other words, adoption of learner as part of one's identity requires that students can make optimal choices and decisions. Arising from this finding is the implication that students who are exposed to environments that require independence arrive at university with higher self-efficacy. This finding is consistent with previous literature that demonstrates a positive relationship between higher academic achievement and self-efficacy (e.g., Bandura \& Locke, 2003). As explained by Komarraju and Nadler (2013), self-efficacy predicts academic achievement because of self-regulation and the ability to persist in the face of challenges. Interestingly, the same attributes that foster academic preparedness may facilitate social readiness.

University is not limited to the academic culture because the social milieu intersects at various points throughout a student's tenure. Social readiness might be captured by individual differences in openness and in being outgoing as the students in the present sample suggest. Indeed, such attributes are socially desirable within the environment of university and of residence life insofar that such attributes facilitate the forming of social networks. As described in the interviews, social networks are fostered by community building activities that include orientation week. Yet social network formation is not limited to the first week and may also be fostered by continued opportunities throughout the first year to enhance inclusivity.

Interestingly, the work ethic developed through employment opportunities also contributes to success in the social domain. Specifically, students who trust themselves and who are independent embody the needed balance between academic and social cultures. These are the students who participate in social events but limit these so as to not unduly impact academic success. Thus, the same students who are academically prepared are often the same ones who are 
socially ready for university. Of course, not all students fall into this category and those who may have the required work ethic may also need to develop a more equitable balance between the academic and social culture.

Overall, the results of the present study contribute to delineating the uniqueness of the transition to university from high school. This transition can be characterized by discontinuity in living conditions, academic expectations, and in students' social world. This study adds to the existing literature in three ways. First, through interviews with first year undergraduate university students, unique features of student readiness were uncovered. Specifically, here advanced placement in high school and employment were identified as pathways to developing the needed work ethic for university. The experiences described by students in the present sample highlight the need for opportunities that nurture independence prior to university.

Second, based on students' perceptions, a successful transition requires a readiness to navigate the discontinuities; unless students are ready, there will be a mismatch in academics or in the social milieu or both. Mismatches will be characterized by disappointment that make evident the changes students face with resultant academic failure and/or loneliness and feelings of anomie. In contrast, a match between an individual student and the academic and social milieus of university are expected to lead to adjustment and success. Third, although often implicit in the literature that examines student readiness and transition from high school, the results presented here underscore that there is no one pathway and that the process is complex. Indeed, the findings here suggest that research attempts to target the "one thing" that will make or break a student as they move from high school to university are misguided. Specifically, as uncovered by the interviews, readiness and a successful transition to university are multifaceted and, thus, require research that targets a wide array of variables; researchers interested in these topics need to provide empirical tests of theoretical models like that of Briggs et al. (2012).

\subsection{Limitations and Future Directions}

This study is not without limitations. First, the sample was derived from a small primarily undergraduate university where the majority of first year students live in residence. Thus, the interviews are not necessarily representative of the experiences of first year students at larger schools. The transition to this university also entails an adjustment to living in residence in a very small rural community. Living in residence typically reduces the need for independence (e.g., preparing meals) and should actually facilitate the transition yet, at the same time, the living accommodations raise additional challenges such as noise levels and sharing of space. In addition to only sampling from one relatively unique university, the sample composition did not necessarily correspond to student populations in general with respect to gender and ethnic distributions. Furthermore, the sample comprised students who had successfully transitioned and who volunteered to participate compromising the generalizability of the findings. Future research with students who drop out would likely contribute to a better understanding of the barriers students face.

Despite these limitations, at least two recommendations can be offered for future research. First, as noted earlier, there is a need to empirically validate a theoretical model of readiness and transition. The present study used Briggs et al.'s (2012) framework as a guide to delineating the process, however, a model that incorporates past research as precursors to the match (or mismatch) between individual students and the academic and social culture of university would assist with identifying additional pathways.

A second potentially interesting direction for future research concerns the assessment of readiness. The literature examining the general domain of student readiness is limited. Often what is not captured are the life skills that students in the present sample identified as characterizing independent living (e.g., scheduling own appointments, laundry). Existing scales that include such skills (e.g., Babbitt \& White, 2002; Unrau, Font, \& Rawls, 2012) are limited because they were developed to target specific populations (e.g., students with learning disabilities), have no available information regarding psychometric properties, and neglect important aspects of readiness including time management. Some like Hawthorne (2012) and Peters (2009) describe the various skills believed to be needed for success in university, including the aforementioned practical skills as well as self-care and independence. Despite these recommendations, an empirically tested measure does not exist for distinctly measuring how ready a student is to begin living independently and working within a challenging institution. Perhaps then future research examining the transition to university should consider pre-emptive assessment of readiness.

\subsection{Conclusions}

The purpose of the present study was to examine students' perceptions of readiness for and transition from high school to university. Whereas it was expected that Briggs et al.'s (2012) process model accurately depicted students' own perceptions and experiences, instead the present results offer a potentially useful avenue for formulating a more inclusive model of readiness and transition. Such a model would characterize readiness as a match/mismatch between an individual's development and the academic and social requisites of university life. As a phenomenological study, the findings of this research highlight the complexities of the pathways to retention and success in university. Although the 
data were replete with common themes that correspond to existing literature, the challenge for future research is to incorporate what is known into a representative and inclusive model.

\section{Acknowledgements}

The research reported here was made possible with funding from a Social Sciences and Humanities Research Council Insight Development Grant. I would like to thank Lauren Kervin for assistance with the interviews.

\section{References}

Adams, T. B., Wharton, C. M., Quilter, L., \& Hirsch, T. (2008). The association between mental health and acute infectious illness among a national sample of 18- to 24-year-old college students. Journal of American College Health, 56, 657-664. http://dx.doi.org/10.3200/JACH.56.6.657-664

Andrews, B., \& Wilding, J. M. (2004). The relation of depression and anxiety to life-stress and achievement in students. British Journal of Psychology, 95, 509-521. http://dx.doi.org/10.1348/0007126042369802

Babbitt, B. C., \& White, C. M. (2002). "R U ready?" Helping students assess their readiness for postsecondary education. Teaching Exceptional Children, 35, 62-66.

Bandura, A. (1977). Self-efficacy: Toward a unifying theory of behavioral change. Psychological Review, 84, 191-215.

Bandura, A., \& Locke, E. A. (2003). Negative self-efficacy and goal effects revision. Journal of Applied Psychology, 88, 87-99.

Briggs, A. R. J., Clark, J., \& Hall, I. (2012). Building bridges: Understanding student transition to university. Quality in Higher Education, 18, 3-21.

Christofides, L. N., Hoy, M., Milla, J., \& Stengos, T. (2015) Grades, aspirations, and postsecondary education outcomes. Canadian Journal of Higher Education, 45, 48-82.

Christofides, L. N., Hoy, M., Milla, J., \& Stengos, T. (2008). The evolution of aspirations for university attendance. In R. Finie, R. E. Mueller, A. Sweetman, \& A. Usher (Eds.), Who goes? Who stays? What matters? Accessing and persisting in post-secondary education in Canada (p. 109-134). Kingston, Canada: McGill-Queen's University Press.

Conrad, M. A. (2005). Aptitude is not enough: How personality and behavior predict academic performance. Journal of Research in Personality, 40, 339-346. http://dx.doi.org/10.1016/j.jrp.2004.10.003

Conley, D. T. (2009). Redefining college readiness, Vol. 3. Retrieved from Educational Policy Improvement Center website: http://www.epiconline.org/files/pdf/RedefiningCR_Vol3.pdf

Crede, M., \& Kuncel, N. R. (2008). Study habits, skills, and attitudes: The third pillar supporting collegiate academic performance. Perspectives on Psychological Science, 3, 425-453.

Dawson, M., \& Pooley, J. A. (2013). Resilience: The role of optimism, perceived parental autonomy support, and perceived social support in first year university students. Journal of Education and training studies, 1, 38-49.

Dyson, R., \& Renk, K. (2006). Freshmen adaptation to university life: Depressive symptoms, stress, and coping. Journal of Clinical Psychology, 62, 1231-1244.

Finnie, R., \& Qiu, H. (2008). The patterns of persistence in post-secondary education in Canada: Evidence from the YITS-B dataset. A MESA Project Research Paper. Toronto, ON: Educational Policy Institute.

Furnham, A., \& Chamorro-Premuzic, T. (2004). Personality, cognitive ability, and beliefs about intelligence as predictors of academic performance. Personality and Individual Differences, 37, 943-955.

Geiser, S., \& Santelices, M. V. (2007). Validity of high-school grades in predicting student success beyond the freshman year: High-school record vs. standardized tests as indicators of four-year college outocmes. Research \& Occasional Paper Series: Center for Studies in Higher Education. 6.07.

Hanlon, C. (2012). State of mind: Addressing mental health issues on university campuses. University Manager, 1-6. http://www.aucc.ca/wp-content/uploads/2012/06/mental-health-state-of-mind-university-manager-article-summer2012.pdf

Hawthorne, T. (2012). Is your child ready to leave home? http://www.parent24.com/Teen_13-18/development_behaviour/Is-your-child-ready-to-leave-home-20110412

Komarraju, M., \& Nadler, D. (2013). Self-efficacy and academic achievement: Why do implicit beliefs, goals, and effort regulation matter? Learning and Individual Differences, 25, 67-72.

O’Connor, M. C., \& Paunonen, S. V. (2007). Big Five personality predictors of post-secondary academic performance. 
Personality and Individual Differences, 43, 971-990. http://dx.doi.org/10.1016/j.paid.2007.03.017

Parker, J. D. A., Summerfeldt, L. J., Hogan, M. J., \& Majeski, S. A. (2004). Emotional intelligence and academic success: examining the transition from high school to university. Personality and Individual Differences, 36, 163-172. http://dx.doi.org/10.1016/S0191-8869(03)00076-X

Peters, R. (2009). How to get your teen ready for college. http://today. msnbc.msn.com/id/14267611/ns/today-parenting_and_family/\#.UM0dP3fEeo0

Prevatt, F., Li, H., Welles, T., Festa-Dreher, D., Yelland, S., \& Lee, J. (2011). The Academic Success Inventory for College Students: Scale development and practical implications for use with students. Journal of College Admission, 7, 26-31.

Richardson, M., \& Abraham, C. (2009). Conscientiousness and achievement motivation predict performance. European Journal of Personality, 23, 589-605. http://dx.doi.org/10.1002/per.732

Richardson, M., Abraham, C., \& Bond, R. (2012). Psychological correlates of university students' academic performance: A systematic review and meta-analysis. Psychological Bulletin, 138, 353-387.

Robbins, S. B., Lauver, K., Le, H., Davis, D., Langley, R., \& Carlstrom, A. (2004). Do psychosocial and studty skill factors predict college outcomes? A meta-analysis. Psychological Bulletin, 130, 261-288.

Sackett, P. R., Kuncel, N. R., Arneson, J. J., Cooper, S. R., \& Waters, S. D. (2009). Does socioeconomic status explain the relationship between admissions tests and post-secondary academic performance? Psychological Bulletin, 135, 1-22. http://dx.doi.org/10.1037/a0013978

Sasaki, M., \& Yamasaki, K. (2007). Stress coping and the adjustment process among university freshmen. Counseling Psychology Quarterly, 20, 51-67.

Slavin, A. (2007). Has Ontario taught its high-school students not to think? University Affairs Available at http://www.universityaffairs.ca/opinion/in-my-opinion/has-ontario-taught-its-high-school-students-not-to-think/

Statistics Canada. (2013). Table 477-0019 - Public postsecondary enrolments, by registration status, Pan-Canadian Standard Classification of Education (PCSCE), Classification of Instructional Programs, Primary Grouping $\left(C I P \_P G\right), \quad$ sex and immigration status, CANSIM. Retrieved from Statistics Canada website: http://www5.statcan.gc.ca/cansim/a05?lang=eng\&id=4770019

Tinto, V. (2012). Completing college: Rethinking institutional action. Chicago: The University of Chicago Press. University of Regina, Transition to University (2015).http://www.uregina.ca/science/student/new-student/trans.html

Unrau, Y. A., Font, S. A., \& Rawls, G. (2012). Readiness for college engagement among students who have aged out of foster care. Children and Youth Services Review, 34, 76-83.

Wintre, M. G., Gates, S. K. E., Pancer, W. M., Pratt, M. S., Polivy, J., Birnie-Lefcovitch, S., \& Adams, G. (2009). The Student Perception of University Support and Structure Scale: Development and validation. Journal of Youth Studies, 12, 289-306. http://dx.doi.org/10.1080/13676260902775085

Wei, M., Russell, D. W., \& Zakalik, R. A. (2005). Adult attachment, social self-efficacy, self-disclosure, loneliness, and subsequent depression for freshman college students: A longitudinal study. Journal of Counseling Psychology, 52, 602-614. http://dx.doi.org/10.1037/0022-0167.52.4.602 


\section{Appendix}

Guiding questions

Why did you come to university?

How committed are you to completing a university education?

Were you satisfied with your performance during the first term here?

What are the academic challenges at university?

What academic skills do you think are necessary to be successful at university?

What are the challenges associated with living (in residence, on your own, with family) when attending university?

What things surprised you about your first year of university?

What were your expectations about first year? Were those expectations met (why or why not?)

Tell me about your goals

What are some things that you wished you knew prior to coming to university?

What do you think are the skills students need when they move away from home for the first time?

Were there particular classes in high school that prepared you for the academic rigor associated with university? Describe

Did family members help to prepare you for university? How?

Did work experiences help to prepare you? How?

What personal attributes should people have before attending university? Why?

This work is licensed under a Creative Commons Attribution 3.0 License. 